\title{
Post-evaluation of Power Measurement and Installation Project
}

\author{
Huadong $\mathrm{Qiu}^{1^{*}}$, Xiong $\mathrm{Li}^{1}$, Yan Wang ${ }^{2}$ and Bin $\mathrm{Zhu}^{1}$ \\ ${ }^{1}$ State Grid Zhejiang Electric Power Company, Hangzhou China 310000 \\ ${ }^{2}$ Zhejiang Huayun Information Technology Co., Ltd, Hangzhou China 310000 \\ ${ }^{*}$ Corresponding author
}

\begin{abstract}
A set of reasonable, scientific and comprehensive index system has been set up for the measurement and installation project of power grids to make post-evaluation from four aspects, including process management and control evaluation, informatization level evaluation, cost management and control evaluation and benefit evaluation. The post-evaluation further improves rationality and compliance of project expenses, promotes the project's lean closed-loop management, as well as enhances the decision-making level and investment returns of power grid enterprises.
\end{abstract}

Keywords-process management and control evaluation; informatization level evaluation; cost management and control evaluation; benefit evaluation

\section{INTRODUCTION}

The project of grid measurement and installation is the project type with the largest and highest percentage in marketing projects, mainly including four types of projects, namely the popularization and application of energy meters, the construction of electricity information collection system, the construction and reconstruction of measurement devices, plus of the collection and construction of "multi-meter integration"; these four types of projects are characterized by small particle size, large number and a wide range. In recent years, reserve declaration funds of the power grid enterprises' measurement and installation projects has increased year by year, and the granted reserve issued funds is generally stable. The project post-evaluation is a systematic and normalized work, which orderly development can not only help managers to prevent projects' management risks ahead of time, avoid the occurrence of irrational funds, as well as improve investment returns, but also promote the project's lean closed-loop management, and then adapt to a new round of reform of the power system and provide valuable experience for the future marketing project. Thus, this paper is based on the measurement and installation projects to implement post-evaluation.

\section{POST-EVALUATION IDEAS AND PRINCIPLES OF GRID MEASUREMENT AND INSTALLATION PROJECT}

This paper takes a closed project of measurement equipment, devices and metered installation of a provincial power company in 2016 as the evaluation object, and regards process management and control evaluation, informatization level evaluation, cost management and control evaluation and benefit evaluation as the main line, as well as makes analysis from the aspects of technology, economy and cost, and then forms a "four-horizontal and three-vertical" post-evaluation system for measurement and installation projects; the post-evaluation system fully covers "horizontal" management processes and deepens "vertical" professional lines.

The project post-evaluation should follow the principles of independence, feedback, practicality, transparency and Scientificcalness. Independence: Post-evaluation should not be influenced by project decision-makers, managers and implementers, so as to ensure the fairness and objectivity of post-evaluation. Feedback: The management of the measurement and installation projects needs to control the objective process with help of feedback information, so as to achieve management goals. The most core task of the post-evaluation is to submit the evaluation conclusions to the corresponding decision-makers, and then provide them with the basis for decision making of projects in the same type. Practicality: Users of post-evaluation can obtain useful information from post-evaluation results; moreover, post-evaluation reports should be readable. Transparency: Post-evaluation reports should be simple and easy to understand, scientific and legible; thus, readers of the report can obtain more useful information. Scientificcalness: The basic data of post-evaluation is true and reliable, evaluation tools and methods are selected reasonably; meanwhile, post-evaluation institutions or personnel should have a solid professional foundation and rich experiences.

\section{POST-EVALUATION OF GRID MEASUREMENT AND INSTALLATION PROJECTS}

\section{A. Measurement and Installation of Project Process Control Evaluation}

1) Pre-project management evaluation

The pre-project management evaluation evaluates the data integrity, content standardization and evaluation efficiency of study feasible compilation and review of the reserved declaration measurement and installation projects in 2016. The main problems, which existed in early stage of all units' measurement and installation projects in 2016, are as follows.

Project approving and evaluation: Some projects have insufficient project approving basis for feasibility studies, and are not implemented according to reserve notices of the year. 
Evaluation of feasibility study reports: projects’ feasibility study templates are uniform in their forms and comprehensive in their contents, but space exists still for improvement in depth. Feasible study review efficiency evaluation: Feasible study review has prominent effect, but the review efficiency needs to be improved.

\section{2) Project implementation management evaluation}

The project implementation management evaluation conducts analysis evaluation from project implementation phases, including project design, bidding management, project contracts, materials management, construction management and completion acceptance etc.

\section{(1) Project Design Evaluation}

The main problems in the design of all units' measurement and installation projects in 2016 are as follows:

Some design units' tender did not be conducted in according to regulations. Design delivered document exists issues, like budget estimates and implementation plan not prepared according to specifications, the quality of the design delivery needing to be improved. Part of the initial design estimate amount is non-compliance, and partial project implementation plans were prepared in delay.

\section{(2) Contract management evaluation}

Evaluation of contract signing time: Issues had been founded by arranging the evaluated project's contracts bid-winning time, contract signing time and other information. Issues included the required number of days of the contract being inconsistent with the completion period of the contract; the actual working duration was inconsistent with the contract requirements, the contract starting time being earlier than the contract's signing time.

Quality evaluation of contract documents: there were issues that a contract corresponded to multiple projects.

(3) Material management evaluation

Material applying evaluation index: The number of measurement equipment out of warehouse is inconsistent with the actual number of installations.

Return evaluation index: picking and return procedures should be strengthened.

Evaluation index for dismantled material handling: dismantled equipment were disposed more standardized.

\section{(4) Construction management evaluation}

Project start-up report evaluation index: there is a project to open, the completion of incomplete reporting issues.

Project process supervision and evaluation indicators: there is incomplete information in the construction process, the project supervision and inspection report did not provide the problem.

Project duration evaluation index: Project duration is reasonable and compliance.

(5) Completion acceptance evaluation
Partial project acceptance information is not complete.

\section{3) Post-project management evaluation}

Post-project management conducted analysis and evaluation from the project settlement, project files and other aspects.

\section{(1) Project settlement evaluation}

Issues existing in project settlement normative indicators: contents of settlement materials are not complete, and didn't prepare in accordance with relevant provisions. Partial procedures of project changes and visa are not compliant.

\section{(2) Project file evaluation}

The project file is an objective reflection of the project's overall situation, and is an important basis for project inspection, evaluation and auditing etc. It was found through data collection that management files of some units' projects were not archived in accordance with the requirements of project management standards.

\section{B. Evaluation of Informationalized Level of Measurement and Installation Projects}

\section{1) Basic data management evaluation}

Cost data doesn't achieve informationalized storage, which is only available for reserved data at present; estimate, budget and settlement of reversed projects are stored in electronic version and paper version. The data is stored by each unit and easily gets lost. There are some difficulties in finding relevant data of the designated projects.

\section{2) Business collaborative evaluation}

Financial estimates and budget preparation tools should be applied fully; assessment tools need to be added. Whole process of marketing projects adopts informatization technologies, among which the budget preparation software has been widely used in the preparation works, including project feasibility study estimate, financial estimates and budget etc. The application of software has provided informatization support and intelligent security for the project cost management, and can reasonably control the project investment, effectively save cost and reduce labor costs, and then greatly enhance the feasibility study estimates and budget preparation efficiency; thus, economic benefits are improved significantly. However, no relevant information technologies support for project review and decision-making at present. There is greater pressure on reviewing experts and project decision-makers only through manual judgments, which cost much time and will affect the implementation progress of the post-project.

Support for full business process informatization means needs to be improved. All work processes of each unit must be completed through different systems according to the collected information.Full-time work of project management involves various information systems; because there are no complete set of systematic processes and relevant instructions.

\section{3) Decision support evaluation}

The level of decision-making informatization needs to be improved. Project managers can't easily get the management 
data through the unified system and the management reports can't be generated automatically.

\section{Cost Management and Control Evaluation of Measurement and Installation Projects}

The cost management and control evaluation of measurement and installation projects mainly deal with four aspects, including feasibility study estimate, initial design estimate, contract price and settlement price.

\section{1) Feasible estimate evaluation}

Feasible study evaluation is mainly made from the indicator of feasibility fund review. The investment difference before and after the feasibility fund review is smaller. Technical reviewers mainly review contents of the project and the reasonability of engineering amount during the review; the technical and financial reviewers mainly review basis of project cost and the reasonableness of the equipment material price. Because technical reviewers are lack of scientific and reasonable forecast values for equipment, like electric energy meters, collection devices and metrology bins, and lack of demand assessment indicators and methods; the reasonableness of work quantities submitted by each unit is difficult to be judged. The material amount of construction and construction volume are configured based on the number of main equipment, material and construction works volume cannot be judged due to the number of main equipment cannot be judged; thus, technical reviewers generally do not adjust the construction volume, which is declared by project units.

\section{2) Initial design estimate evaluation}

The initial design estimate evaluation was mainly conducted from the deviation between feasibility study review and implementation project. The implementation programs (initial design) are design documents to make further refinement of the various sub-projects, which are based on the project feasibility study reports, as well as meet requirements of tender equipment order and project implementation. The initial design estimates are important bases for project investment control, and should be commissioned to qualified design units with the appropriate qualifications. The implementation programs (initial design) should be based on the approved projects' feasibility study reports, and it is forbidden to expand the scale or raise the standard without authorization. The initial design estimate should be controlled within the feasibility study investment. If the initial estimate exceeds that of the feasibility study, the analysis and explanation should be made for the exceeding reasons, which should be agreed by the feasibility study review units and change advices should be given. Anomalies are analyzed and summarized after consulting relevant compilation staff and management personnel, details are as follows: 1)The source of project funding changes. 2) There are problems when the projects are packaged and unpackaged. 3) The amount of implementation program is larger than that of feasibility study approval. 4) The amount of the implementation program is less than that of feasibility study approval.

\section{3) Contract price evaluation}

The evaluation of contract price was mainly conducted from the indicator of deviation of implementation plan amount and bid-winning contract price. All units' bid-winning contract prices are reasonable and compliant.

\section{4) Settlement price evaluation}

The evaluation of the settlement price was mainly conducted from deviation between the contract price and the settlement price.Main issues in the settlement price of all units' measurement and installation are as follows: 1) The items not included in this project were listed at the time of settlement. 2) Contents of the project were changed, and the actual amount of construction was different from that of the original contract, and change contact forms were not provided as the basis for adjustment. 3) Settlement comprehensive price of the project exceeded the maximum price limit. 4) The quality of settlement compilation needed to be improved.

\section{Benefit Evaluation of Measurement and Installation Projects}

The benefit evaluation of measurement and installation projects was mainly conducted from three aspects, including economic benefits, technical benefits and social benefits. Economic benefit evaluation: the input efficiency of measurement and installation projects settled in 2016 was estimated via data envelopment analysis tools, plus of the selection and analysis of input-output indicators; thus, the economic benefits of measurement and installation projects were evaluated. Technical benefit evaluation: it was evaluated from 3 aspects including pass rate of measurement device configuration, error rate of measurement device failure, advantages of measuring devices. Social benefits evaluation: it was evaluated from 3 aspects including customer satisfaction degree, impact of enterprises' own development, social and economic development.

\section{CONCLUSIONS}

Grid measurement installation project plays an important role in grid operation. This paper builds up a set of reasonable, scientific and comprehensive index system from four aspects, including process management and control evaluation, informatization level evaluation, cost control evaluation, benefit evaluation and so on. The rationality and compliance of project expense use are further improved through post-evaluation, and the closed-loop management of projects is promoted, the management of enterprises and allocation of resources are improved. Moreover, the decision-making level and investment returns of enterprises are improved, they provide basis for relevant departments to formulate and perfect measures.

\section{REFERENCES}

[1] Hu Diangang. Research on multi-dimensional post-evaluation system for new energy power generation project $[\mathrm{J}]$. Power System Protection and Control, February, 2015, 10-17.

[2] Tang Xiaolan. Research on effective construction of post-evaluation index system of power engineering [J].Electric Power Information, October, 2017, 176-177.

[3] Ming ZENG, Zi-zhi Xu, Song Xue, Xiao-li Zhu. Grid project quantities management system based on bill of quantities [J] Electric Power, 2012, 45(2): $70-73$. 